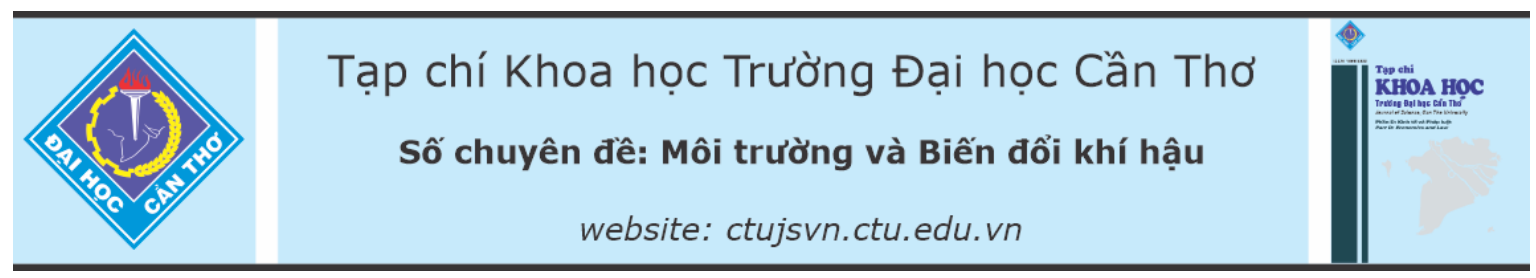

DOI:10.22144/ctu.jsi.2021.023

\title{
ĐÁNH GIÁ MộT SỐ CHİ TIÊU NƯớC MặT Ở CÁC MÔ HİNH CANH TÁC TẠI CÙ LAO DUNG - SÓC TRĂNG
}

\author{
Nguyễn Ngọc Bảo Châu*, Dương Minh Truyền, Lý Văn Lợi và Trương Hoàng Đan \\ Khoa Môi trường và Tài nguyên Thiên nhiên, Trường Đại học Cần Thơ \\ *Người chịu trách nhiệm về bài viết: Nguyê̂n Ngọc Bảo Châu (email: nguyenngocbaochau2908@gmail.com)
}

\section{Thông tin chung:}

Ngày nhận bài: 12/04/2021

Ngày nhận bài sưa: 23/08/2021

Ngày duyệt đăng: 15/11/2021

\section{Title:}

Assessing some parameters of surface water quality in the farming models in $\mathrm{Cu}$ Lao Dung - Soc Trang

\section{Tù khóa:}

Chất lượng nước mặt, Cù Lao Dung, mô hình canh tác, quyết định canh tá

\section{Keywords:}

Cu Lao Dung, farming

decision, farming model, water quality

\begin{abstract}
The study was conducted to evaluate some parameters of surface water quality in the typical farming models in Cu Lao Dung, Soc Trang province, contributing to providing information for local agricultural decisions. The evaluated parameters of surface water quality include $\mathrm{pH}$, dissolved oxygen $(D O)$, temperature $\left({ }^{\circ} C\right)$, electrical conductivity $(E C)$, salinity, $B O D_{5}{ }^{20}$, total nitrogen and total phosphorus. Water samples were collected at four representative farming models in the surveyed area, namely Shrimp Pond (whiteleg shrimp farming), longan orchard, mango orchard and coconut orchard in the rainy seasons (10/2019) and in the dry season (3/2020). The results indicated the water quality in the surveyed area met the requirement for agricultural irrigation according to QCVN08:2015/BTNMT (column B1). However, the high salinity level $(2.8-3.3$ ppt) in the dry season may affect the growth of fruit trees and the development of orchard models. Besides, it is necessary to control $B O D_{5}{ }^{20}$ in the shrimp farming model in the dry season to limit the negative effects on the water quality when discharged to the surrounding environment.
\end{abstract}

\section{TÓM TÁT}

Nghiên cứu được thục hiện nhằm đánh giá một số chỉ tiêu về chất lương nước mặt ở các mô hình canh tác nông nghiệp diển hình vùng thượng nguồn huyện Cù Lao Dung, tỉnh Sóc Trăng, góp phần cung cấp thông tin cho các quyết định canh tác nông nghiệp tại địa phương. Các thông số chất lượng nuơớc mặt được đánh giá bao gồm $\mathrm{pH}$, oxy hòa tan (DO), nhiệt độ $\left({ }^{\circ} \mathrm{C}\right)$, độ dẫn điện $(E C)$, độ mặn, $B O D_{5^{20}}$, tổng đạm và tổng lân. Mầu nuớc được thu tại bốn mô hình sản xuất đại diện tại khu vục nghiên cứu là ao tôm (tôm thẻ chân trắng), vườn nhãn, vườn xoài và vườn dì̀a trong mùa mura (10/2019) và mùa khô (3/2020). Kết quả nghiên cúu cho thấy, chất lượng nước tại khu vực nghiên cứu được đánh giá là đáp úng được cho nhu cầu tuói tiêu phục vu cho sản xuất nông nghiệp theo QCVN08:2015/BTNMT (cột B1). Tuy nhiên, độ mặn trong nước mặt vào mùa khô cao $(2,8-3,3$ ppt) có thể gây ảnh huởng đến khả năng sinh truởng và phát triển của các mô hình trồng cây ăn quả. Bên cạnh đó, hàm luợng $B O D_{5}^{20}$ trong mô hình nuôi tôm vào mùa khô cần được kiểm soát nhằm hạn chế các ảnh huơong bất lợi đến chất lượng môi trường nước khi xả thải ra môi trường xung quanh. 


\section{GIỚI THIỆU}

Nước là một yếu tố quan trọng đóng vai trò thiết yếu đối với tất cả các sinh vật đang sống trên trái đất. Nước được sử dụng trong hầu hết các hoạt động thường nhật của con người, trong sản xuất công nghiệp, nông nghiệp, các hoạt động giải trí,... Trong nông nghiệp, nước giữ vai trò quyết định khả năng sinh trưởng và phát triển của cây trồng. Cù Lao Dung (CLD), tỉnh Sóc Trăng là một huyện cù lao nằm trên sông Hậu thuộc vùng nhiệt đới gió mùa cận xích đạo có nhiệt độ cao đều trong năm và hai mùa mưa - khô rõ rệt. Mùa mưa bắt đầu từ tháng 5 đến tháng 11 , mùa khô từ tháng 12 đến tháng 4 năm sau (Trần Minh Bình, 2019). Do nằm gần cửa biển, chịu ảnh hưởng từ chế độ thủy triều của biển Đông, trong những năm gần đây, huyện đang chịu ảnh hưởng trực tiếp bởi tình trạng xâm nhập mặn (Cổng thông tin điện tử tỉnh Sóc Trăng, 2020). Theo đó, các khu vực nước ngọt điển hình như xã An Thạnh $\mathrm{I}$, khu vực đầu nguồn của CLD đang có xu thế thâm canh trong sản xuất nông nghiệp từ các mô hình cây ăn trái nước ngọt đến các mô hình nuôi tôm thẻ chân trắng (TCT) nước mặn. Các mô hình này sử dụng nguồn nước tưới tiêu, phục vụ cho các mô hình canh tác đều lấy trực tiếp từ nguồn nước lân cận như sông và kênh rạch. Ngược lại, các mô hình canh tác cũng thải trực tiếp ra hệ thống sông và kênh rạch. Sự kết nối nguồn nước trực tiếp giữa các mô hình và hệ thống sông, kênh rạch gây ra các nguy cơ tạo ra nguồn ô nhiễm cho các mô hình canh tác xung quanh. Chính vì thế, trong bài báo này, các kết quả quan trắc về chất lượng nước của một số mô hình canh tác đại diện ở vùng nước ngọt được trình bày nhằm đánh giá tổng quan về hiện trạng chất lượng nước làm căn cứ hỗ trợ cho các quyết định phục vụ trong canh tác nông nghiệp tại địa phương.

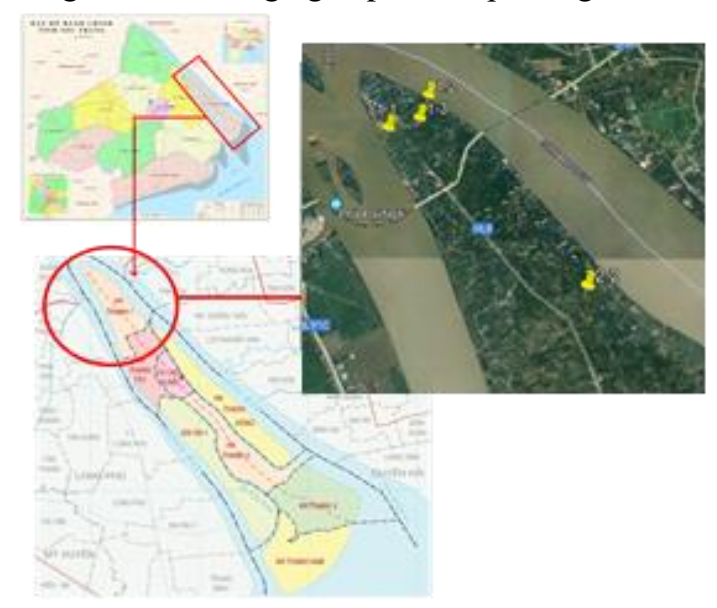

\section{Hình 1. Vị trí thu mẫu tại khu vực nghiên cứu}

\section{PHƯƠNG PHÁP NGHIÊN CÚU}

Nghiên cứu được thực hiện tại khu vực xã An Thạnh I thuộc huyện Cù Lao Dung vào thời điểm tháng 10/2019 - 5/2020. Trước khi tiến hành thu mẫu, một khảo sát vào thời điểm tháng 8/2019 đã được thực hiện nhằm xác định tổng quan các mô hình canh tác có tại khu vực nghiên cứu.

Thu mẫu 02 đợt (mùa mưa và mùa khô) với tổng cộng 08 mẫu nước được thu theo phương pháp mẫu gộp tại 04 mô hình canh tác đại diện thuộc khu vực nghiên cứu bao gồm mô hình nuôi tôm TCT, trồng dừa, trồng nhãn và trồng xoài. Bốn mô hình canh tác này chiếm diện tích lớn nhất tại khu vực nghiên cứu nên được lựa chọn. Đối với mô hình nuôi tôm, mẫu nước được thu tại cống thải của ao nuôi ra sông.

\section{Bảng 1. Mô tả các mô hình đại diện và tọa độ các điểm thu mẫu}

\begin{tabular}{|c|c|c|c|c|}
\hline \multirow{2}{*}{ TT } & \multirow{2}{*}{ Tên mô hình } & \multirow{2}{*}{ Mô tả mô hình } & \multicolumn{2}{|c|}{ Tọa độ (UTM) } \\
\hline & & & Vĩ độ & Kinh độ \\
\hline 1 & $\begin{array}{l}\text { Mô hình trồng } \\
\text { xoài }\end{array}$ & $\begin{array}{l}\text { Mô hình áp dụng giống xoài Cát Chu với diện tích } \\
\text { là } 0,3 \text { ha. Cây có độ tuổi từ } 3-4 \text { năm, mật độ trồng } \\
\text { thưa, mỗi cây cách nhau } 5-8 \mathrm{~m} \text {. }\end{array}$ & 9.747837 & 106.083383 \\
\hline 2 & $\begin{array}{l}\text { Mô hình trồng } \\
\text { dừa }\end{array}$ & $\begin{array}{l}\text { Giống dừa ta được sử dụng trên diện tích đất } 01 \text { ha. } \\
\text { Cây có độ tuổi } 6-7 \text { năm, mật độ trồng thưa, mỗi } \\
\text { cây cách nhau } 5-7 \mathrm{~m} \text {. }\end{array}$ & 9.758000 & 106.088989 \\
\hline 3 & $\begin{array}{l}\text { Mô hình trồng } \\
\text { nhãn }\end{array}$ & $\begin{array}{l}\text { Mô hình trồng giống nhãn IDO trên diện tích đất } 01 \\
\text { ha. Cây có độ tuồi từ } 1-2 \text { năm, mật độ trồng thưa, } \\
\text { mỗi cây cách nhau } 5-6 \mathrm{~m} \text {. }\end{array}$ & 9.751628 & 106.087858 \\
\hline 4 & $\begin{array}{l}\text { Mô hình nuôi } \\
\text { tôm TCT }\end{array}$ & $\begin{array}{l}\text { Tôm TCT được nuôi bán thâm canh với diện tích ao } \\
\text { là } 0,5 \text { ha, độ sâu ao khoảng } 2-3 \mathrm{~m} \text {, có lót bạt, nuôi } \\
\text { tôm TCT với mật độ khoảng } 50-60 \mathrm{con} / \mathrm{m}^{2} \text {. }\end{array}$ & 9.720993 & 106.116408 \\
\hline
\end{tabular}


Tại mỗi điểm thu mẫu chính, thu 05 mẫu đại diện cho mô hình đó, sau đó, gộp lại thành một mẫu. Mẫu nước được thu ở tầng mặt, cách mặt nước $15 \mathrm{~cm}$, cách bờ kênh, rạch tại vị trí thu $0,5 \mathrm{~m}$. Mẫu sau khi thu được chứa trong can nhựa, dán nhãn ghi rõ ký hiệu mẫu cho từng vị trí thu, tiến hành trữ lạnh ở $4^{\circ} \mathrm{C}$ trong thời gian 1 ngày trước khi vận chuyển đến phòng thí nghiệm.

\subsection{Phương pháp đo nhanh tại hiện trường}

Tại mỗi vị trí thu mẫu, sử dụng các thiết bị đo nhanh đo cách bờ kênh, rạch từ $0,5 \mathrm{~m}-1 \mathrm{~m}$. Tiến hành ghi nhận số liệu khi các thông số trên máy đo ổn định trong 15-20 giây.

Bảng 2. Các chỉ tiêu và thiết bị sử dụng đo trực tiếp tại hiện trường

\begin{tabular}{|c|c|c|}
\hline TT & Chỉ tiêu & Thiết bị đo \\
\hline 1 & $\mathrm{pH}$ & Máy đo $\mathrm{pH}$ meter $\mathrm{AD} 12$ \\
\hline 2 & DO & Máy đo EzdO 7031 \\
\hline 3 & Nhiệt độ & $\begin{array}{l}\text { Máy đo EC/TDS/TEMP - } \\
\text { COM } 100\end{array}$ \\
\hline 4 & EC & $\begin{array}{l}\text { Máy đo EC/TDS/TEMP - } \\
\text { COM } 100\end{array}$ \\
\hline 5 & Độ mặn & $\begin{array}{l}\text { Máy đo độ mặn EXTECH - } \\
\text { EC } 170\end{array}$ \\
\hline
\end{tabular}

\subsection{Phương pháp phân tích trong phòng thí nghiệm}

Sau khi tiến hành thu các mẫu nước và gửi phân tích tại phòng thí nghiệm của Trung tâm Kỹ thuật Tiêu chuẩn Đo lường Chất lượng Cần Thơ, các phương pháp phân tích được sử dụng, trình bày ở Bảng 3 .

Bảng 3. Các thông số và phương pháp phân tích

\begin{tabular}{cll}
\hline TT & Chỉ tiêu & Phương pháp \\
\hline 1 & BOD $_{5}^{20}$ & SMEWW 5210:2012 \\
2 & $\begin{array}{l}\text { Đạm tổng số (tính } \\
\text { theo N) }(\mathrm{mg} / \mathrm{L})\end{array}$ & Theo hướng dẫn của \\
& $\begin{array}{l}\text { TCVN 6638:2000 } \\
\text { Lân tồng số (tính } \\
\text { theo P) (mg/L) }\end{array}$ & $\begin{array}{l}\text { SMEWW 4500 - P.B } \\
\text { \& E:2012 }\end{array}$ \\
\hline
\end{tabular}

\section{KẾT QUẢ VÀ THẢO LUẬN}

\subsection{Nhiệt độ}

Kết quả trong Hình 2 cho thấy nhiệt độ trung bình của nước tại bốn mô hình canh tác vào mùa mưa dao động từ $28,9-31,3^{\circ} \mathrm{C}$. Cao nhất tại mô hình canh tác ao tôm và thấp nhất tại mô hình canh tác nhãn. Nhiệt độ trung bình khoảng $29,8^{\circ} \mathrm{C}$. Vào mùa khô, nhiệt độ tại khu vực nghiên cứu cao hơn so với mùa mưa, từ $30-30,6^{\circ} \mathrm{C}$. Đối với các mô hình canh tác trong khu vực nghiên cứu, mô hình nuôi tôm TCT nhạy cảm cao với nhiệt độ nước. Khoảng chênh lệch nhiệt độ giữa mùa mưa và mùa khô là 3,6 độ là tương đối lớn. Theo nghiên cứu của Kim Văn Vạn và Đoàn Thị Ninh (2019), nhiệt độ nước phù hợp cho sinh trường và phát triển của tôm $\mathrm{TCT}$ nằm trong khoảng từ $25^{\circ} \mathrm{C}-32^{\circ} \mathrm{C}$. Vào mùa khô, nhiệt độ đạt trên $33^{\circ} \mathrm{C}$, gây ảnh hưởng lớn đến sự phát triển của con tôm. Theo Trần Lưu Khoang và ctv. (2020), ở nhiệt độ $34^{\circ} \mathrm{C}$, tôm sẽ dễ mẫn cảm với vi khuẩn Vibrio parahaemolyticus với tỷ lệ chết tích luỹ là $96,7 \pm 2,9 \%$.

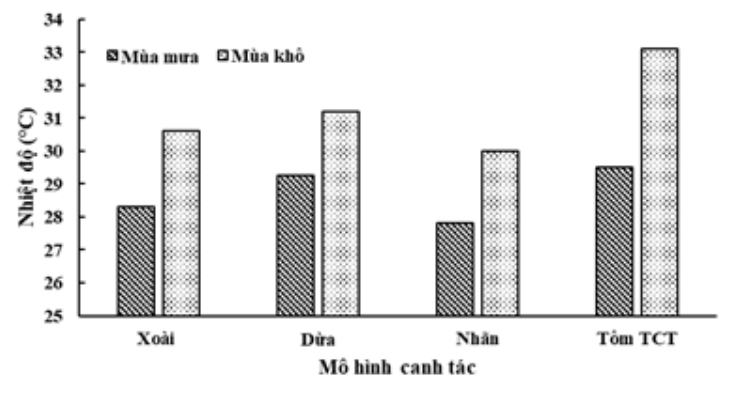

Hình 2. Nhiệt độ nước tại các mô hình canh tác

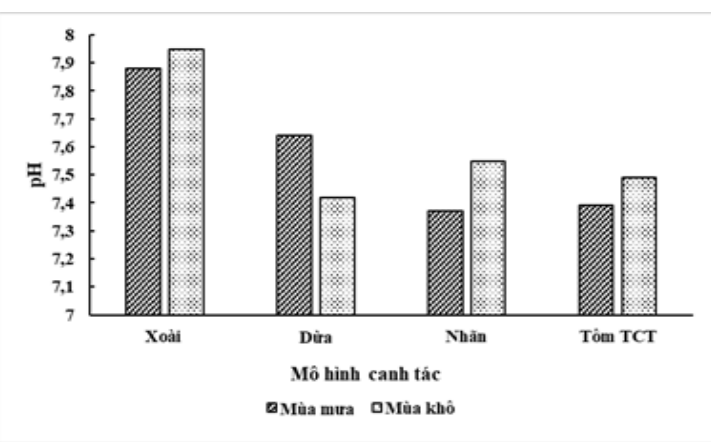

Hình 3. Giá trị pH nước tại các mô hình canh tác

\subsection{Giá trị pH}

Kết quả quan trắc $\mathrm{pH}$ của các mẫu nước ở các mô hình canh tác được thể hiện qua Hình 3. Giá trị $\mathrm{pH}$ trung bình của nước tại bốn mô hình canh tác vào mùa mưa dao động từ $7,37-7,88$. Giá trị $\mathrm{pH}$ cao nhất tại mô hình canh tác xoài và thấp nhất tại mô hình canh tác tôm. Vào mùa khô, giá trị $\mathrm{pH}$ trong nước tại khu vực nghiên cứu nằm trong khoảng từ 7,40 đển 7,95 . Theo Lê Văn Quân và ctv. (2010), giá trị $\mathrm{pH}$ thích hợp cho cây xoài phát triển tốt nằm trong khoảng 5,5-7. Do đó, mức $\mathrm{pH}$ tại mô hình canh tác xoài cần điều chỉnh lại để cây xoài có thể đạt năng suất cao. Bên cạnh đó, theo Bùi Thị Mỹ Hồng và ctv. (2020), cây nhãn sinh trưởng tốt trong điều kiện đất thoát nước, tơi xốp, $\mathrm{pH}$ nước khoảng $5,5-6,5$. Như vậy, giá trị $\mathrm{pH}$ nước tại mô hình trồng nhãn vượt 0,96 so với mức $\mathrm{pH}$ cho phép cao nhất là 6,5 . Đối với mô hình canh tác dừa, theo Nguyễn Bảo Vệ (2011), cây dừa chịu được $\mathrm{pH}$ từ 5,2 đến 8 nhưng 
thích hợp nhất là 6 đến 7 . Khoảng pH thích hợp cho nước trong ao tôm là từ 7,8 đến 8,5 . Như vậy, $\mathrm{pH}$ nước tại mô hình nuôi tôm thấp hơn so với yêu cầu để cho tôm đạt điều kiện sinh trưởng và phát triển lý tưởng (mùa mưa 7,39 và mùa khô 7,49 ).

Khoảng chấp nhận được của $\mathrm{pH}$ nước tưới nằm trong khoảng từ 5,5 đến 7,5 . Nếu $\mathrm{pH}$ cao hơn 7,5 thì chất lượng cây trồng sẽ bị ảnh hưởng (Zaman et al., 2019). Qua quá trình thu mẫu kết hợp phỏng vấn người dân tại khu vực nghiên cứu cho thấy các nông hộ thường sử dụng vôi khử chua cho đất trong thời gian dài, đây cũng là yếu tố ảnh hưởng đến giá trị pH nước tại các mô hình canh tác.

Nhìn chung, giá trị pH nước đo được tại các mô hình canh tác đều nằm trong khoảng giới hạn phù hợp với nhu cầu sử dụng nước của các mô hình sản xuất. So sánh với QCVN 08:2015/BTNMT (Bộ Tài nguyên và Môi trường, 2015), giá trị $\mathrm{pH}$ nước tại khu vực nghiên cứu đạt yêu cầu cột $\mathrm{A} 1(6-8,5)$ sử dụng cho mục đích cấp nước sinh hoạt (sau khi áp dụng xử lý thông thường), bảo tồn động thực vật thủy sinh và các mục đích khác.

\subsection{Hàm lượng oxy hòa tan}

Giá trị oxy hòa tan (DO) trong nước của bốn mô hình canh tác ở mùa mưa (Hình 4 ) dao động từ 0,8 $\mathrm{mg} / \mathrm{L}$ đến $3,5 \mathrm{mg} / \mathrm{L}$. Cao nhất tại mô hình nuôi tôm và thấp nhất tại mô hình canh tác nhãn. Ở mùa khô, DO dao động từ $1,0 \mathrm{mg} / \mathrm{L}$ đến $4,7 \mathrm{mg} / \mathrm{L}$. Vào mùa khô, khả năng trao đổi nước giữa hệ thống kênh rạch và nước trong mô hình tốt hơn do có sự chênh lệch mực nước lớn nhờ vào thuỷ triều và nguồn nước từ thượng nguồn sông Mekong đổ về, do đó dẫn đến sự chênh lệch DO giữa hai mùa. Riêng mô hình nuôi tôm có $\mathrm{DO}$ cao cả hai mùa là do người dân sử dụng quạt tạo oxy cho ao nuôi. Theo Trần Văn Thánh (2015), hàm lượng oxy hòa tan tốt nhất cho tôm nên nằm trong khoảng giữa $3,5 \mathrm{mg} / \mathrm{L}$ đến bão hòa. Đối với các mô hình trồng cây ăn quả, cũng cần lưu ý thông thoáng nguồn nước tưới tiêu để tránh ứ đọng làm giảm $\mathrm{DO}$ gây ảnh hưởng đến các loài thuỷ sinh như các loài cá nuôi kết hợp với mô hình.

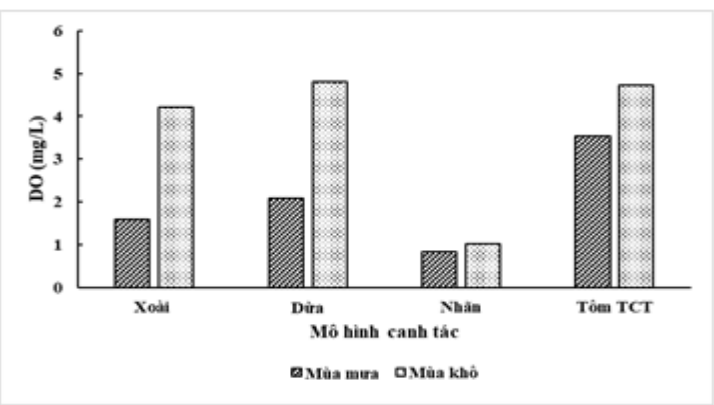

Hình 4. Giá trị DO tại các mô hình canh tác
So sánh với QCVN 08:2015/BTNMT (Bộ Tài nguyên và Môi trường, 2015), giá trị $\mathrm{DO}$ trong nước mặt tại bốn mô hình canh tác được đánh giá phù hợp cho mục đích tưới tiêu cột B1.

\section{4. Độ mặn}

Hình 5 thể hiện giá trị độ mặn trung bình tại bốn mô hình canh tác là $1,7 \mathrm{ppt}$. Trong đó, mô hình xoài có độ mặn trung bình thấp nhất là 1,66 ppt và cao nhất tại 03 mô hình còn lại với giá trị độ mặn trung bình tương đương là 1,71 ppt. Trong đó, số liệu ghi nhận được vào mùa mưa cho thấy nồng độ muối có trong nước bị pha loãng khiến độ mặn tại các mô hình đều ở mức thấp, dao động từ $0,2 \mathrm{ppt}$ đến 0,5 ppt. Vào mùa khô, độ mặn tăng vọt, dao động từ 2,8 ppt đến 3,3 ppt, nguyên nhân là do xâm nhập mặn từ biển Đông (Tổng cục Phòng chống Thiên tai - Bộ Nông nghiệp và Phát triển Nông thôn, 2020).

Theo Sommay (2017), nước có độ mặn từ 0,02 ppt đến 0,5 ppt được xếp loại là nước ngọt, phù hợp cho nhu cầu phát triển của các loại cây trồng tại các mô hình canh tác như nhãn, nừa và xoài vào mùa mưa. Vào mùa khô, độ mặn đã tăng vọt gây nhiều rủi ro cho mô hình trồng nhãn (có ngưỡng chịu mặn thấp < $1 \mathrm{ppt}$ ). Dừa với xoài có ngưỡng chịu mặn cao hơn (>3 ppt), tuy nhiên với điều kiện nước mặn như vậy sẽ không thuận lợi cho cây phát triển tốt. Theo Huỳnh Thanh Tới và Nguyễn Thị Hồng Vân (2018), tôm TCT có thể sống ở độ mặn từ 0,5 ppt đến $45 p p t$ và phát triển thích hợp ở độ mặn khoảng 10 - 15ppt. Khi các ao tôm TCT thải nước ra sẽ gây ra nhiều rủi ro cho các mô hình canh tác cây ăn trái xung quanh, đặc biệt trong điều kiện mùa khô, thiếu nước ngọt canh tác sẽ càng dễ bị nhiễm mặn. Do đó, công tác qui hoạch và quản trị nguồn nước cần tránh mâu thuẫn giữa việc sử dụng nguồn nước ngọt để trồng cây ăn trái với nguồn nước bị nhiễm mặn do nước thải từ ao tôm.

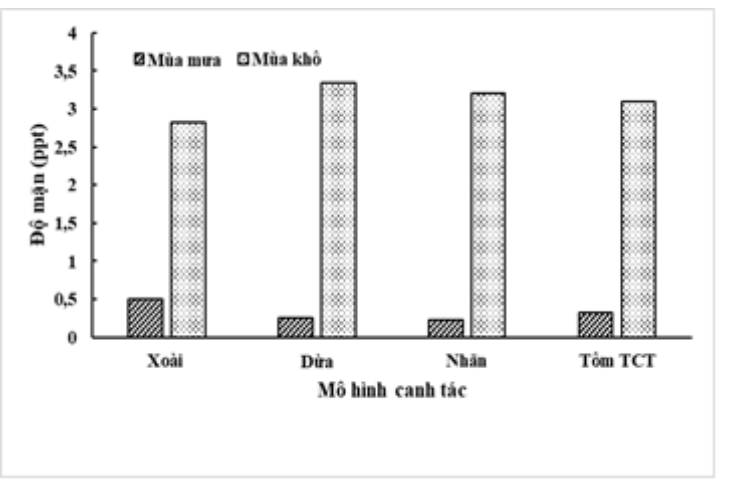

Hình 5. Độ mặn trong nước tại các mô hình canh tác 
Hai mô hình canh tác trong cùng một khu vực đang có nhu cầu về nguồn nước trái ngược nhau. Nếu tăng độ mặn để đạt được điều kiện sinh trưởng của con tôm thì lại rủi ro cho mô hình canh tác khác. Do đó, những bài toán chi phí - lợi ích là cần thiết để qui hoạch mô hình canh tác đồng bộ cho khu vực này.

\subsection{Giá trị EC}

Giá trị EC hiện diện trong nước tại bốn mô hình canh tác vào mùa mưa thấp, từ $0,16 \mathrm{mS} / \mathrm{cm}$ đến 0,69 $\mathrm{mS} / \mathrm{cm}$. Vào mùa khô, do chịu ảnh hưởng của xâm nhập mặn, giá trị EC trong nước tại bốn mô hình canh tác tăng cao hơn nhiều so với mùa mưa (từ 5,56 $\mathrm{mS} / \mathrm{cm}$ đến 6,55 mS/cm) (Hình 6).

Theo Võ Thành Toàn và ctv. (2007), độ dẫn điện của nước (EC) có mối quan hệ rất lớn với độ mặn của nước. Dựa trên kết quả ghi nhận được độ mặn trong nước thu được tại bốn mô hình được trình bày ở trên cho thấy, giá trị $\mathrm{EC}$ trong nước tại bốn mô hình so với giá trị độ mặn là hoàn toàn phù hợp. Tuy nhiên, trong nông nghiệp, việc duy trì EC ở mức ổn định là điều cần thiết. Tùy vào chỉ số $\mathrm{EC}$ cao hay thấp có thể ảnh hưởng đến tốc độ hấp thu khoáng chất và phát triển của cây trồng.

Nghiên cứu của Rusydi (2019) đã chỉ ra rằng độ mặn của nước phụ thuộc vào hai giá trị $\mathrm{EC}$ và tổng chất rắn hòa tan (TDS), tuy nhiên hai giá trị này không phải lúc nào cũng tương quan tuyến tính với nhau, có nhiều yếu tố tác động như chất rắn lơ lửng trong nước, nhiệt độ,....

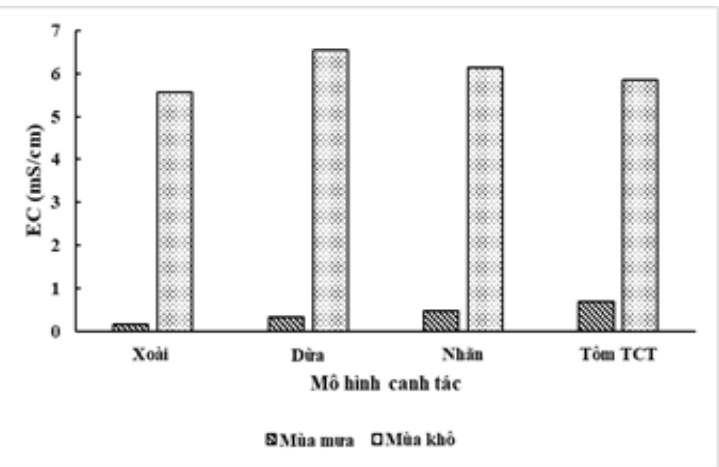

\section{Hình 6. Giá trị EC trong nước tại các mô hình} canh tác

\subsection{Hàm lượng $\mathrm{BOD}_{5}{ }^{20}$}

Giá trị $\mathrm{BOD}_{5}{ }^{20}$ hiện diện trong nước tại bốn mô hình canh tác dao động từ $5 \mathrm{mg} / \mathrm{L}$ đến $12,5 \mathrm{mg} / \mathrm{L}$ vào mùa mưa và từ $8 \mathrm{mg} / \mathrm{L}$ đến $17 \mathrm{mg} / \mathrm{L}$ vào mùa khô. Trong đó, mô hình canh tác xoài có giá trị thấp nhất và mô hình canh tác nhãn có giá trị cao nhất (Hình 7).
Theo Nguyễn Mỹ Hoa (2010), giá trị $\mathrm{BOD}_{5}{ }^{20}$ có trong các ao nuôi trồng thủy sản thường dao động từ $5 \mathrm{mg} / \mathrm{l}$ đến $20 \mathrm{mg} / \mathrm{l}$, chỉ số $\mathrm{BOD}_{5}{ }^{20}$ càng cao thì mức độ phong phú chất hữu cơ càng cao. Giá trị $\mathrm{BOD}_{5}{ }^{20}$ đo được tại mô hình canh tác tôm ở mức thấp $(<11$ $\mathrm{mg} / \mathrm{L}$ ) vào mùa mưa nên hàm lượng chất hữu cơ dễ phân hủy thấp nhưng lại cao vào mùa khô. Nếu quá trình phân hủy các chất hữu cơ chậm có thể dẫn đến tình trạng nhiễm bẩn ao nuôi. Bên cạnh đó, quá trình phân hủy chất hữu cơ diễn ra chậm cũng có thể gây ứ đọng và nhiễm bẩn nguồn nước dùng cung cấp cho cây trồng dẫn đến cây phát triển kém, năng suất thấp. Do đó, việc theo dõi và kiểm soát thường xuyên giá trị $\mathrm{BOD}_{5}{ }^{20}$ trong nguồn nước tại các mô hình canh tác cần được chú ý.

Ngoài ra, so sánh với QCVN 08: 2015/BTNMT (Bộ Tài nguyên và Môi trường, 2015), hàm lượng $\mathrm{BOD}_{5}^{20}$ trong nước ghi nhận được tại bốn mô hình canh tác được xếp vào cột giá trị $\mathrm{B} 1$ - Dùng cho mục đích tưới tiêu thủy lợi, phù hợp phục vụ cho vấn đề tưới tiêu cây trồng của người dân.

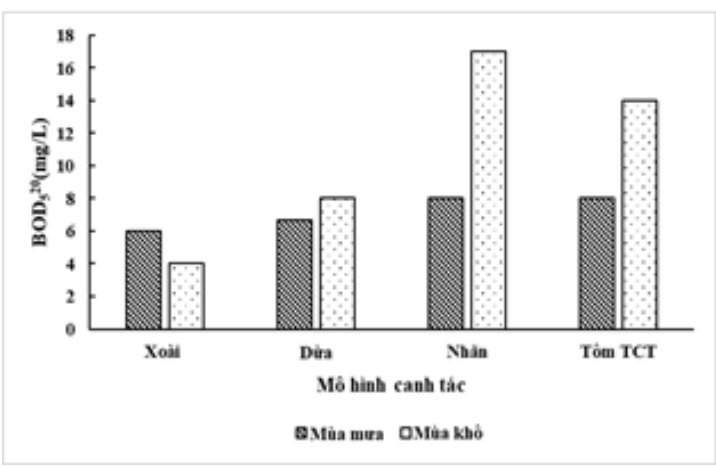

\section{Hình 7. Giá trị BOD520 trong nước tại các mô hình canh tác}

\subsection{Tổng đạm}

Kết quả phân tích tổng đạm ở các mô hình canh tác được trình bày ở Hình 8 . Giá trị đạm tổng của bốn mô hình dao động từ 1,4 đến $4,2 \mathrm{mg} / \mathrm{L}$ vào mùa mưa và $2,0-3,1 \mathrm{mg} / \mathrm{L}$ vào mùa khô. Trong đó, giá trị đạm tổng cao nhất tại mô hình canh tác nhãn và thấp nhất là mô hình trồng dừa. Hàm lượng đạm tổng đo được trong nước tại mô hình trồng nhãn cao gấp 2 lần so với giá trị đạm tổng trung bình của ba mô hình còn lại. Theo nghiên cứu của Phạm Văn Hảo (2012) về vấn đề sử dụng phân đạm tại CLD, người dân tại địa phương sử dụng loại và liều lượng phân bón cho cây trồng theo kinh nghiệm cá nhân. Do đó, lượng phân bón dư thừa tồn dư trong đất ngấm vào nước hoặc rửa trôi theo nước mưa xuống kênh rạch và nguồn nước lân cận. Điều này dẫn đến sự chênh lệch lớn về tỷ lệ đạm tổng có trong nước 
giữa các mô hình với nhau. Bên cạnh đó, các hộ dân nuôi tôm TCT thường tiến hành trữ nước ao nuôi, chỉ cấp thêm $3-6$ lần/vụ và xả nước sau $2-3$ vụ nuôi (Lê Trần Tiểu Trúc và ctv., 2018). Vì vậy, lượng thức ăn và chất thải của tôm tích lũy dưới đáy ao cũng là một trong các yếu tố ảnh hưởng đến hàm lượng đạm trong nước tại mô hình nuôi tôm TCT dẫn đến sự chênh lệch lớn giữa hai mùa mưa và khô.

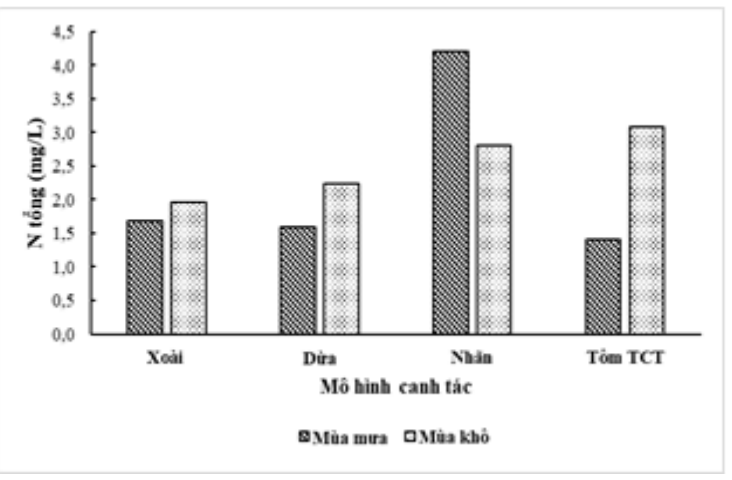

Hình 8. Giá trị Nitơ tổng tại các mô hình canh tác

\subsection{Tổng lân}

Hàm lượng lân tổng có trong nước ghi nhận được tại bốn mô hình dao động từ $0,4 \mathrm{mg} / \mathrm{L}$ đến 0,7 $\mathrm{mg} / \mathrm{L}$ vào mùa mưa và nằm trong khoảng $0,2-1,4$ $\mathrm{mg} / \mathrm{L}$ (Hình 9). Theo Nguyễn Thanh Hùng và Nguyễn Thị Thu Huyền (2010), hiện tượng phú dưỡng là một dạng suy giảm chất lượng nước mà lân là yếu tố chính. Hàm lượng lân có trong nước tại mô hình trồng nhãn cao hơn so với các mô hình còn lại có thể do lượng phân bón sử dụng không đồng đều ở các mô hình cùng với lượng nước rửa trôi vào mùa khô ít dẫn đến tồn đọng nhiều trong nước. So sánh với QCVN08:2015/BTNMT (Bộ Tài nguyên và Môi trường, 2015), giá trị lân tổng ghi nhận tại 4 mô hình xếp vào cột $\mathrm{B} 1$, nước dùng cho tưới tiểu hoặc mục đích khác yêu cầu chất lượng thấp.

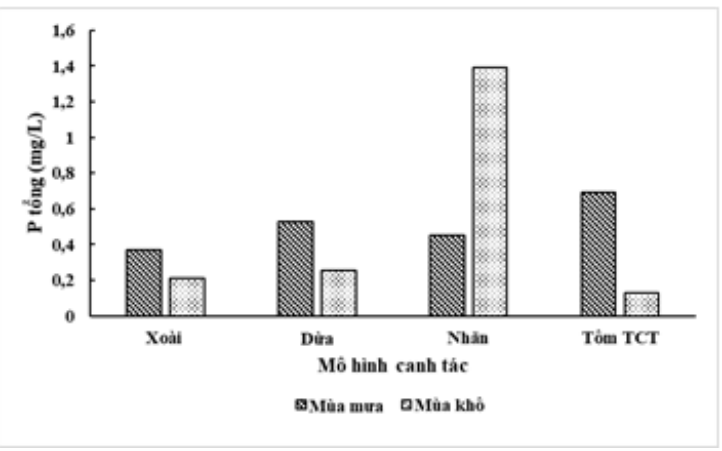

Hình 9. Hàm lượng lân tổng trong nước ở các mô hình canh tác

\section{KỄT LUẬN VÀ KIẾN NGHI}

Chất lượng nước tại các vị trí nghiên cứu trong hai mùa mưa và khô đáp ứng được nhu cầu phục vụ cho tưới tiêu nông nghiệp so với QCVN 08:2015/BTNMT (Bộ Tài nguyên và Môi trường, 2015). Nhiệt độ trong ao tôm vào mùa khô cao hơn so với điều kiện phát triển của tôm. Độ mặn trong nước vào mùa khô tăng vọt tại các mô hình canh tác sẽ gây ảnh hưởng đến sự phát triển của cây trồng, đặc biệt là cây nhãn. $\mathrm{BOD}_{5}{ }^{20}$ trong nước tại mô hình nuôi tôm TCT ở mức cao $14 \mathrm{mg} / \mathrm{L}$ vào mùa khô, yếu tố này có thể gây ảnh hưởng đến chất lượng nước thủy vực và các mô hình canh tác xung quanh nếu thải trực tiếp ra môi trường xung quanh.

Khu vực nghiên cứu có độ mặn ở cả hai mùa không đáp ứng được nhu cầu cho mô hình nuôi tôm phát triển tốt. Do đó, địa phương cần có biện pháp quy hoạch mô hình nuôi tôm hợp lý và có biện pháp xử lý và quản lý nước thải để tránh gây tác động đến các mô hình canh tác khác, đặc biệt là cây nhãn. Ngoài ra, các giải pháp cảnh báo sớm về xâm nhập mặn vào mùa khô cũng cần được triển khai đến các hộ dân để có kế hoạch quản lý nước tưới hiệu quả.

\section{LỜI CẢM TẠ}

Nghiên cứu này được thực hiện dưới sự hỗ trợ kinh phí từ Dự án Nâng cấp Trường Đại học Cần Thơ VN14-P6 bằng nguồn vốn vay ODA từ chính phủ Nhật Bản.

\section{TÀI LIỆU THAM KHẢO}

Bộ Tài nguyên và Môi trường. (2015). QCVN 08MT:2015/BTNMT: "Quy chuẩn Kỹ thuật Quốc gia về Chất lượng nước mặt”. http://cem.gov.vn/storage/documents/5d6f3ecb26 484qcvn-08-mt2015btnmt.pdf

Bùi Thị Mỹ Hồng, Huỳnh Trí Đức \& Huỳnh Văn Thành. (2019). Kỹ thuật trồng Nhãn. Truy cập ngày 10 tháng 09 năm 2019. Địa chỉ https://sites.google.com/site/tailieukn/trongtrot/ky-thuat-trong-nhan

Cổng thông tin điện tử tỉnh Sóc Trăng. (2020). Nông dân Cù Lao Dung ứng phó với hạn, mặn. Truy cập ngày 24/3/2020. Địa chỉ: https://soctrang.gov.vn/ubndstg/4/469/54333/302199/Tin-huyen--thi-xa-thanh-pho/Nong-dan-Cu-Lao-Dung-ung-phovoi-han--man.aspx

Huỳnh Thanh Tới \& Nguyễn Thị Hồng Vân. (2018). Ảnh hưởng của chu kì biến động độ mặn lên chu kì lột xác và sinh trưởng cua tôm thẻ chân trắng (Litopenaeus vannamei) giai đoạn giống. Tạp chi Khoa học Nông nghiệp Việt Nam, 16(5), 435 - 432. 
Kim Văn Vạn \& Đoàn Thị Ninh. (2019). Thử nghiệm thuần hóa và nuôi thương phẩm tôm thẻ chân trắng (Litopenaesu vanamei) qua đông trong ao nuôi nước ngọt tại Hưng Yên. Tạp chí Khoa học Nông nghiệp Việt Nam, 17(1), 38 - 46.

Lê Văn Quân, Đỗ Văn Chuông, Trần Thanh Phong \& Trương Quốc Luận. (2010). Kỹ thuật trồng Xoài. Truy cập ngày 10 tháng 9 năm 2019. Địa chỉ: Địa chỉ http://en.hcmuaf.edu.vn/rttc-81441/vn/-cay-xoai.html

Lê Trần Tiểu Trúc, Nguyễn Thị Bé Ly, Đặng Thị Thúy Ái, Nguyễn Thị Hồng Ngọc, Đặng Thị Thu Trang, Phạm Việt Nữ \& Ngô Thụy Diễm Trang. (2018). Hiện trạng quản lý và xử lý chất thải từ ao nuôi tôm thẻ chân trắng (Litopenaeus vannamei) thâm canh tại tỉnh Sóc Trăng, Bạc Liêu và Cà Mau. Tạp chí Khoa học Trương Đại hoc Cần Tho: 54(1B), 82-91.

Zaman M., Shahid S. A. \& Heng L. (2018). Irrigation Water Quality. In Zaman M., Shabbir S. A. \& Heng L. Guideline for Salnity Assesment, Mitigation and Adaption Using Nuclear and Related Techniques, (pp. 113 - 131). Springer, Cham. https://doi.org/10.1007/978-3319-96190-3_5.

Nguyễn Bảo Vệ, Trần Văn Hâu \& Lê Thanh Phong. (2011). Giáo trình cây công nghiệp dài ngày. NxB Đại học Cần Thơ.

Nguyễn Mỹ Hoa. (2010). Khảo sát tính chất môi trường đất, nước của mô hình nuôi tôm sú (Penaeus monodon) kết hợp lúa, màu trên vùng đất phèn nhiễm mặn ở Hậu Giang. Tạp chi Khoa hoc Đại hoc Cần Tho, 16b, 80-87.

Nguyễn Thanh Hùng \& Nguyễn Thị Thu Huyền. (2010). Nghiên cứu diễn biến chất lượng nước hồ Đại Lải tỉnh Vĩnh Phúc qua một năm đo đạc và thu thập dữ liệu. Tạp chí Khoa hoc kỹ thuật Thủy lợi và Môi trường, 31, 57-64.

Phạm Văn Hảo. (2012). Phưong pháp bón phân đạm cho mía theo bảng so màu lá LCC (leaf color chart) trên đất phù sa huyện Cù Lao Dung tỉnh
Sóc Trăng (Luận văn thạc sĩ). Trường Đại học Cần Thơ.

Rusydi A. F. (2019). Correlation between conductivity and total dissolved solid in various type of water: A review. IOP Conference series: Earth and Environmental Science, 118 (2018) 012019. https://doi.org/10.1088/17551315/118/1/012019

Sommay P. (2017). Đánh giá hiện trạng và đề xuất các giải pháp nâng cao chất luợng nuớc sông Năm Xong, huyện Văn Viên, tỉnh Viên Chăn, nước Công hòa Dân chủ Nhân dân Lào (Luận văn đại học). Trường Đại học Lâm nghiệp.

Tổng cục Phòng chống Thiên tai - Bộ Nông nghiệp và Phát triển Nông thôn. (2020). Báo cáo Tổng hợp tình hình hạn hán, xâm nhập mặn khu vụcc miền Nam 2019 - 2020. Truy cập ngày 21/9/2021. Địa chỉ: http://phongchongthientai.mard.gov.vn/Pages/ba o-cao-tong-hop-tinh-hinh-han-han-xam-nhapman-khu-vuc-mien-nam-2019--2020.aspx

Trần Minh Bình. (2019). Nghiên cúu đề xuất giải pháp mở rộng mạng luoói cấp nuớc huyện Cù Lao Dung, kết hợp ưng dụng hệ thống thông tin địa lý GIS quản lý mạng lưới (Luận văn thạc sĩ). Trường Đại học Thủy lợi - Thành phố Hồ Chí Minh.

Trần Văn Thánh. (2015). Khảo sát khía cạnh kinh tế và kỹ thuật mô hình nuôi tôm thẻ chân trắng (Litopenaeus vannamei) thâm canh tại huyện Bình Đại-Bến Tre (Luận văn đại học). Trường đại học Tây Đô.

Trần Lưu Khoang, Ngô Chí Nguyện, Trương Quốc Phú \& Đặng Thị Hoàng Oanh. (2020). Ânh hưởng của nhiệt độ lên sự mẫn cảm của tôm thẻ chân trắng (Litopenaeus vannamei) với vi khuẩn Vibrio parahaemolyticus. Tap chi Khoa hoc Truờng Đại hoc Cần Tho; 56(1), 38-44.

Võ Thành Toàn, Chheng Phen \& Eric Baran. (2007). Nghiên cứu đặc điểm một số chỉ tiêu môi trường nước và thành phần loài tôm, cá tự nhiên ở tỉnh Bạc Liêu. Tạp chí khoa học Trương Đại học Cần Tho, 8, $139-148$. 